\title{
Construção e calibração de lisímetros de alta precisão
}

\author{
Rogério T. de Faria ${ }^{1}$, Fernando de S. M. Campeche ${ }^{2} \&$ Eduardo Y. Chibana ${ }^{1}$
}

\begin{abstract}
RESUMO
Os lisímetros de pesagem determinam a evaporação ou evapotranspiração pelo balanço de massa de água e são considerados padrões para aferição dos demais métodos. Para a obtenção de medidas confiáveis, sua calibração deve ser realizada no local de uso. O objetivo deste trabalho foi apresentar detalhes da construção de uma bateria de dez lisímetros de pesagem, calibrá-los e testar sua capacidade de medir variações de massa de água em condições de campo. Cada lisímetro tinha dimensões de 1,4 m de largura, 1,9 m de comprimento e 1,3 m de profundidade e era colocado sobre uma balança com alavancas de redução de peso e uma célula carga, cujo sinal era registrado por um sistema de aquisição de dados. A calibração foi feita utilizando-se recipientes de massa conhecida, representando uma faixa de variação de massa equivalente a $150 \mathrm{~mm}$. Os resultados mostraram excelente linearidade entre as variações de massa e voltagem, para todos os lisímetros testados e não se constatou histerese. As medidas de evapotranspiração mostraram precisão para detecção de mudanças de massa de pelo menos $0,1 \mathrm{~mm}$, em intervalos iguais ou maiores que $1 \mathrm{~h}$, adequado para a maioria das aplicações de campo.
\end{abstract}

Palavras-chave: balanço hídrico, evapotranspiração, uso consuntivo

\section{Construction and calibration of high precision lysimeters}

\begin{abstract}
By measuring the water mass balance, weighing lysimeters are considered as the standard for other methods in the determination of evaporation or evapotranspiration. In order to obtain accurate measurements, the lysimeters must be calibrated in situ, to establish the relationship between load cell signal and mass variation of the system. This work had as objective to present construction details of a battery of ten weighing lysimeters, to calibrate them and to test their performance to measure variations of water mass under field conditions. Each lysimeter had 1.4 x $1.9 \mathrm{~m}$ surface dimensions by $1.3 \mathrm{~m}$ depth, being supported by a lever-load cell scale, whose signal was recorded by an electronic system. The calibration was performed using recipients of known mass quantity, in a range equivalent to $150 \mathrm{~mm}$. The results showed an excellent linearity between mass and voltage variations for all lysimeters and there was no hysteresis. The measurements of evapotranspiration showed a precision as high as $0.1 \mathrm{~mm}$, by averaging readings in intervals of 10 min or longer, which is suitable for most of applications in agrometeorology and agricultural engineering.
\end{abstract}

Key words: water balance, evapotranspiration, consumptive use 


\section{INTRODUÇÃO}

A quantificação do fluxo de vapor d’água para a atmosfera proveniente de superfícies úmidas, como áreas cultivadas ou em pousio, é de grande interesse para determinação das necessidades hídricas de cultivos e disponibilidade hídrica do solo. Dentre os vários métodos disponíveis os lisímetros determinam a evaporação ou evapotranspiração pelo balanço de massa ou volume de água e são considerados padrões para aferição dos demais.

Os lisímetros, desenvolvidos há mais de 60 anos, consistem de tanques contendo solo representativo da área de interesse e são utilizados sobretudo para medir os componentes do balanço de água no sistema solo-planta-atmosfera, sob tratos culturais e condições climáticas específicas. Os lisímetros podem apresentar diversas formas e sistemas de medidas, porém os que usam mecanismos de pesagem são considerados os mais precisos e sensíveis para a determinação direta da evapotranspiração, pelo balanço de massa de água.

Nos últimos anos, o desenvolvimento da eletrônica disponibilizou sensores mais precisos, robustos e baratos, incluindo-se as células de carga, que podem ser usadas para construção de lisímetros de pesagem de alta precisão, além de sistemas de aquisição e armazenamento de dados, que facilitam consideravelmente a operação contínua dos lisímetros em trabalhos de monitoramento.

Para a obtenção de leituras confiáveis os lisímetros devem, preferencialmente, ser calibrados in situ, por adição e retirada de massa de quantidades previamente conhecidas. A calibração tem por finalidade estabelecer a relação entre o sinal elétrico de saída da célula de carga (geralmente expresso em $\mathrm{mV}$ ) e a massa do sistema, além da verificação da linearidade e histerese da célula de carga. A descrição detalhada dos procedimentos para calibração de lisímetros de pesagem é dada por Howell et al. (1995), que calibraram um lisímetro de $9 \mathrm{~m}^{2}$ para determinação da evapotranspiração de referência em grama, no Texas, USA. Também, Meshkat et al. (1999) reportaram calibração de um lisímetro de pesagem utilizando um sistema de contrapeso acoplado a uma célula de carga de capacidade para $45 \mathrm{~kg}$.

No Brasil, Silva et al. (1999), Campeche (2002) e Fietz et al. (2003) calibraram e testaram lisímetros de pesagem com montagem direta sobre as células de carga para verificação da linearidade e histerese do equipamento em campo. Esses autores encontraram boa concordância entre variações de massa e leituras dos sinais das células de carga, indicando a alta precisão dos dispositivos usados.

Este trabalho tem como objetivo apresentar detalhes da construção de uma bateria de dez lisímetros de pesagem, baseados em célula de carga e sistema de redução de massa, calibrar esses lisímetros e testar sua capacidade de medir variações de massa de água em condições de campo.

\section{MATERIAL E MÉTODOS}

\section{Construção e instalação dos lisímetros}

Dez lisímetros de pesagem foram construídos e instalados no IAPAR, em Londrina, PR, Figura 1A; cada lisímetro contém tanques duplos retangulares, sendo o tanque externo construído de paredes de concreto de $0,1 \mathrm{~m}$ de espessura, com $2 \mathrm{~m}$ de comprimento, 1,5 m de largura e $2 \mathrm{~m}$ de profundidade, enquanto o tanque interno foi construído em chapa de açocarbono de 5,1 mm de espessura, com dimensões de 1,4 $\mathrm{m}$ de largura, 1,9 m de comprimento e 1,3 m de profundidade; sua borda superior é reforçada com cantoneiras de 37,5 mm de largura e o fundo com vigas de apoio de $40 \mathrm{~mm}$, confeccionado com um declive de $0,05 \mathrm{~m} \mathrm{~m}^{-1}$ no sentido das laterais para o centro, visando facilitar o escoamento de água; as paredes do tanque metálico foram revestidas com massa plástica e pintadas, para evitar vazamento e corrosão.

Cada tanque foi sustentado por uma balança de fabricação comercial (Balanças Açores, Cambe, PR) constituída, na parte superior, por um quadro metálico em viga I laminada de 0,1 m, do mesmo comprimento e largura do tanque e, na parte inferior, por um conjunto de transmissão de forças composto de quatro conjuntos oscilantes, ligados a um mecanismo de três alavancas metálicas de redução de massa, apoiadas em cinco suportes de apoio, colocados sobre fundações de concreto. No sistema de transmissão de forças o atrito, devido à mobilidade das estruturas, é minimizado pelo conjunto de "navalha” e coxim, em cada ponto de articulação (Figura 1B).

O sistema de redução de pesos proporciona redução aproximada de 45 vezes a massa total, que é registrada por células de carga do modelo SV, a tração, de capacidade de $100 \mathrm{~kg}$, seladas contra umidade e com dispositivo para compensação contra variações de temperatura no zero e na calibração na faixa de 0 a $50{ }^{\circ} \mathrm{C}$. Segundo o fabricante (Alfa Instrumentos Eletrônicos Ltda., São Paulo, SP), a sensibilidade das células de carga é de $2+/-10 \% \mathrm{mV} \mathrm{V}^{-1}$ e a acuracidade é de $0,02 \%$ do fundo de escala.

O sinal elétrico de saída da célula de carga é conectado ao sistema de aquisição de dados, constituído de um multiplexador de canais diferenciais (AM 416 Relay Multiplexer, Campbell Sci., Logan - USA) e um datalogger (CR10X Campbell Sci., Logan - USA). A potência elétrica para o sistema é fornecida pela rede local, porém se utilizou uma bateria de $12 \mathrm{~V}$ para assegurar o suprimento de energia, em caso de interrupção. Os dados armazenados podem ser transferidos para um computador ou para um módulo de memória usando-se como interface o programa PC208W.

Cada tanque foi preenchido com uma camada de cerca de 0,10 m com a seqüência de brita, seguida de areia e depois uma manta do tipo bidim; o volume restante foi ocupado com solo recomposto do local, obtido pela escavação de uma trincheira na área vizinha, retirando-se camadas de 0,15 m para preenchimento dos tanques, seguindo-se a mesma sequência que a do perfil original; a cada camada procedeu-se a uma ligeira compactação, na tentativa de reproduzir a densidade original do solo.

O sistema de drenagem canaliza a água acumulada na camada de brita da base do tanque metálico para reservatórios constituídos de dois tubos de PVC de 0,3 m de diâmetro e 1,9 m de comprimento (Figura 1C), suspensos sob o quadro superior do sistema de pesagem. Enquanto armazenada nos reservatórios, a água de drenagem continua sendo 

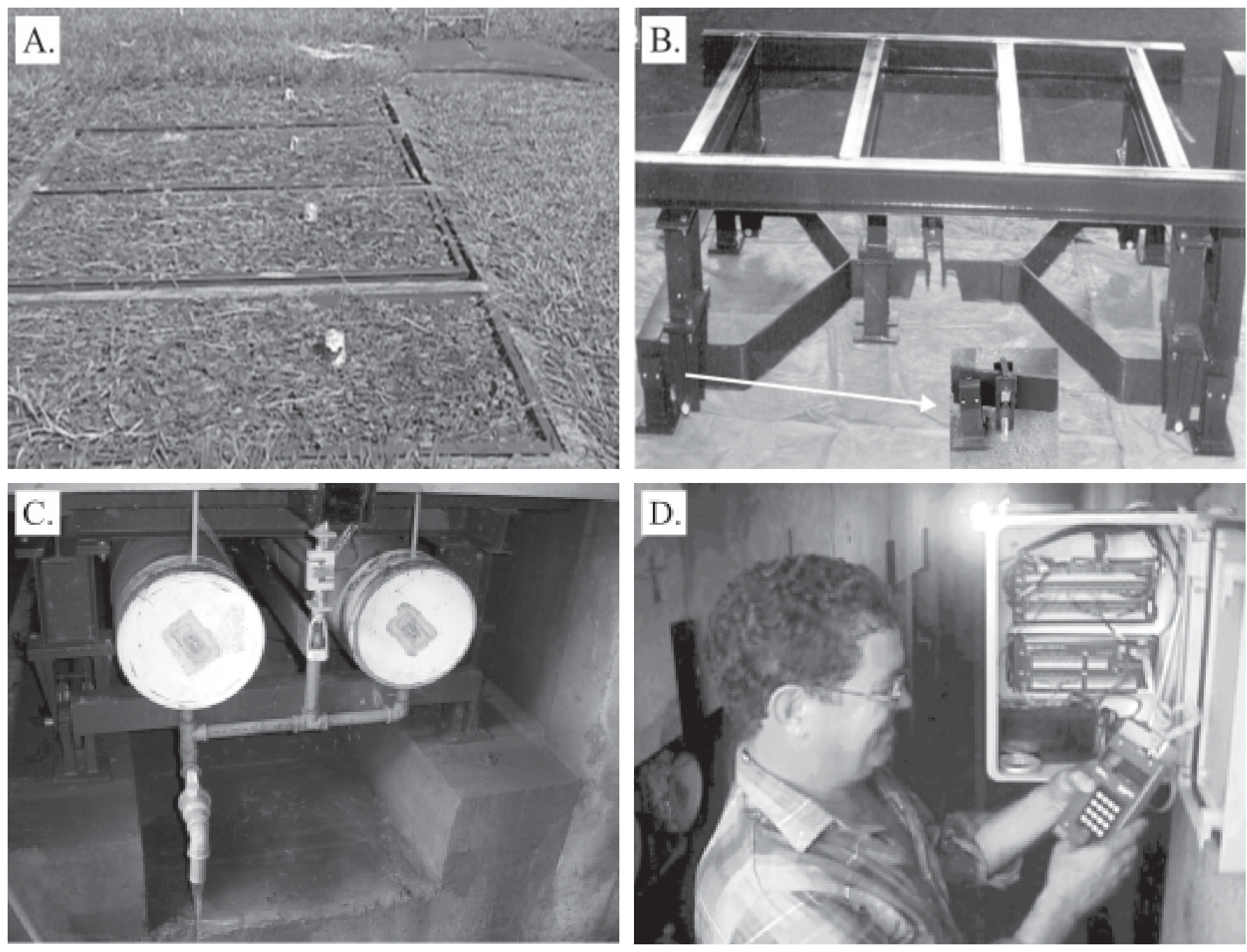

Figura 1. (A) Vista geral dos lisímetros instalados; (B) balança com sistema de redução de massa e navalha/coxim no detalhe; (C) reservatório de água de drenagem e registros de saída, e (D) sistema de aquisição de dados

parte da massa contabilizada pelo sistema de pesagem até que seja aberto o registro de saída.

\section{Calibração e teste dos lisímetros}

Após se selecionar a célula de carga dentre as várias opções do mercado, adquiriu-se um exemplar para se realizar um ensaio de laboratório tendo em vista verificar se a mesma serviria para o sistema a ser construído. No ensaio de laboratório utilizaram-se pesos-padrões para a obtenção de acréscimos de carga de zero a $100 \mathrm{~kg}$, em intervalos de $5 \mathrm{~kg}$, e descarga de 100 a zero kg, com decréscimos também de $5 \mathrm{~kg}$. Utilizando-se o sistema de aquisição de dados em cada patamar de peso, tomaram-se leituras do sinal de saída das células de carga a cada três segundos, armazenando-se as médias a cada minuto.

A calibração de campo foi realizada com a superfície dos lisímetros cobertos com lona plástica para evitar a mudança de massa do sistema devido à evaporação da água do solo. Para minimizar o efeito do vento durante a calibração, utilizou-se quebra-vento ao redor de cada lisímetro, constituído de uma lona plástica de cerca de $0,7 \mathrm{~m}$. No período de calibração, de 6 a 10/07/2003, a velocidade do vento registrada na Estação Meteorológica do IAPAR, localizada ao lado do experimento, variou de 94 a $250 \mathrm{~km} \mathrm{~d}^{-1}$. Esses valores foram próximos ou menores que os valores médios normais $\left(210 \mathrm{~km} \mathrm{~d}^{-1}\right)$.

Iniciou-se o ensaio com a obtenção da leitura de voltagem em cada lisímetro descarregado (somente com o solo de preenchimento); a seguir, a variação de massa foi obtida com a adição e retirada de sacos plásticos com areia secada ao ar, hermeticamente fechados, de diferentes massas e pesados em balança de acuracidade de 0,01 g. Os acréscimos ou retiradas de massa foram realizados a cada $2 \mathrm{~min}$, descartando-se da análise as leituras registradas durante o primeiro minuto, já que incluíam as oscilações provocadas pela variação de massa. Desenvolveu-se um programa para automatizar as leituras e armazenar os resultados no datalogger. As leituras foram realizadas a cada três segundos, com média a cada minuto e com opção para alta resolução como voltagem de excitação (input range de 7,5 mV e $2.500 \mathrm{mV}$ ).

Os pesos foram acrescentados aos lisímetros em seqüência de carga de massa equivalente a $7 \mathrm{~mm}$ de água sobre a superfície do lisímetro (2,66 m²), obtida pela adição de 4 sacos de areia de 4,655 kg, até alcançar $70 \mathrm{~mm}$, seguidos de acréscimos 
de $1 \mathrm{~mm}$, produzidos pela adição de um saco de areia de $2,66 \mathrm{~kg}$, até atingir a massa equivalente a $80 \mathrm{~mm}$. A partir de $80 \mathrm{~mm}$, os acréscimos voltaram a ser de $7 \mathrm{~mm}$, até atingir $150 \mathrm{~mm}$; em seguida, os sacos com areia foram retirados em intervalos também de 2 min, na mesma sequência da adição, até a descarga completa e, assim, foram obtidos 60 pares de pontos para confecção da curva de calibração ( $\mathrm{mV} \mathrm{x} \mathrm{mm).}$

\section{RESULTADOS E DISCUSSÃO}

O ensaio de calibração da célula de carga em laboratório mostrou correlação significativa $\left(\mathrm{r}^{2}>0,999\right)$ entre as variações de massa e a resposta de voltagem (Figura 2). Os coeficientes angulares da reta calculados para o conjunto de pontos nos cursos carga e descarga foram muito próximos entre si (45,017 e 45,022 $\mathrm{kg} \mathrm{mV}^{-1}$, respectivamente), podendo ser representados por coeficiente único, obtido pela regressão do conjunto de todos os dados da análise $\left(45,020 \mathrm{~kg} \mathrm{mV}^{-1}\right)$. A Figura 2 mostra, ainda, que houve baixa dispersão entre os valores de potencial elétrico medidos nos cursos de carga e descarga, indicando pequenos desvios $(<0,03 \mathrm{~kg})$ e sem histerese, o que confirma as especificações do fabricante.

No ensaio de campo os valores dos coeficientes de determinação foram todos significativos e próximos da unidade (Tabela 1), indicando que as variações na quantidade de massa foram estreitamente relacionadas com as variações da voltagem, medidas nas células de carga. A linearidade entre as variações de massa e voltagem foi também excelente para todos os lisímetros testados e não se constatou histerese, como mostrado na Figura 3, para quatro dos dez aparelhos testados. A alta precisão para determinação de variações de massa de água foi comprovada pelos baixos valores de erro absoluto, que variaram entre 0,07 e 0,42 mm (Tabela 1 ). Resultados semelhantes foram encontrados por Howell et al. (1995) e Allen \& Fischer (1991), utilizando metodologia semelhante na calibração.

Os valores do coeficiente angular da equação de regressão entre massa e voltagem para os diferentes aparelhos variaram entre 778,08 e 890,49 $\mathrm{mm} \mathrm{mV}^{-1}$ (Tabela 1 ), sendo es-

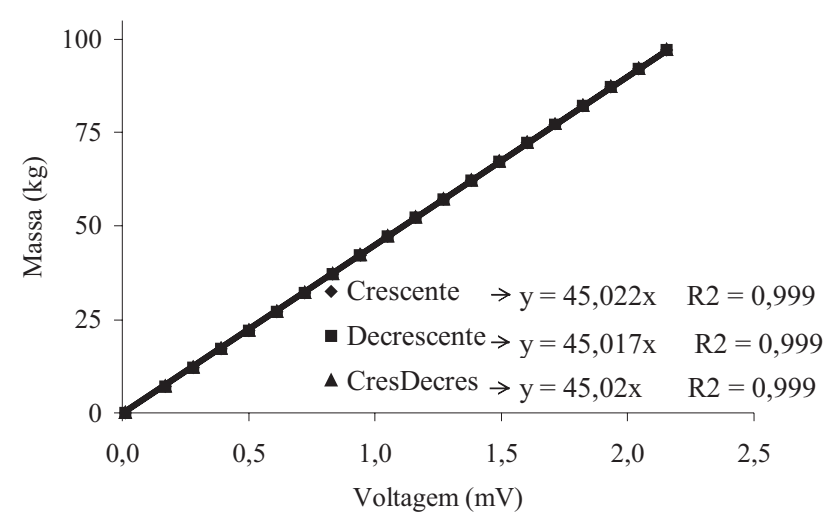

Figura 2. Variação de massa em função da variação da voltagem medida na célula de carga para os ciclos de carga, descarga e todo o conjunto de dados, acompanhado dos respectivos coeficientes angulares e de determinação
Tabela 1. Coeficientes de regressão linear da reta $y=a x+b$ e respectivos coeficientes de determinação $\left(r^{2}\right)$ entre massa (y) e voltagem (x), juntamente com erro absoluto médio para a estimativa de massa, para os dez lisímetros testados

\begin{tabular}{ccccc}
\hline Lisímetro & $\mathbf{a}$ & $\mathbf{b}$ & $\mathbf{r}^{2}$ & $\mathbf{E}$ \\
1 & 845,26 & $-2171,61$ & 1,0000 & 0,1014 \\
2 & 876.97 & -2198.29 & 0,9998 & 0,4229 \\
3 & 801,01 & $-2173,86$ & 1,0000 & 0,1222 \\
4 & 886,17 & $-2263,26$ & 1,0000 & 0,1658 \\
5 & 890,49 & $-2203,01$ & 1,0000 & 0,1165 \\
6 & 778,36 & $-2145,07$ & 1,0000 & 0,1821 \\
7 & 859,87 & $-2136,39$ & 1,0000 & 0,1874 \\
8 & 778,08 & $-2117,74$ & 1,0000 & 0,3131 \\
9 & 796,43 & $-2160,20$ & 1,0000 & 0,0744 \\
10 & 828,26 & $-2145,41$ & 1,0000 & 0,0764 \\
\hline
\end{tabular}

sas diferenças devidas principalmente às características específicas do extensômetro elétrico de cada célula de carga e das dimensões das alavancas de redução de peso. Os valores dos coeficientes b, obtidos na regressão, oscilaram entre 2.117,74 a 2.263,26 (Tabela 1), sendo as diferenças devidas à massa estática (peso morto) de cada conjunto.

A comparação de similaridade dos coeficientes angulares entre pares de retas não mostrou diferenças estatisticamente significativas pelo teste $\mathrm{t}(\alpha \leq 0,001)$, porém as novas equações de regressão obtidas para representar cada par de lisímetros, apresentaram maior dispersão que as retas calibradas individualmente, para cada aparelho. Este resultado, associado à inevitável diferença de "peso morto" entre cada aparelho, indica que é mais adequado se usar as equações próprias para cada lisímetro durante os trabalhos de monitoramento, ao invés de equação única para todos os aparelhos.

Para demonstrar a capacidade dos lisímetros descritos neste trabalho em monitorar componentes do balanço hídrico apresentam-se, na Figura 4, a variação diária da massa e as taxas horárias da evapotranspiração correspondentes, em um dos lisímetros, durante o período de três dias do mês de março de 2003. Neste período, a evapotranspiração de referência calculada pelo método de Penman \& Monteith usando-se dados medidos na estação meteorológica próxima ao lisímetro foi de $5,2 \mathrm{~mm}$ para os dois primeiros dias e de $4,4 \mathrm{~mm}$ para o terceiro dia. Nos primeiro e segundo dias, como não houve chuva nem se realizou a drenagem do lisímetro, a variação de massa ocorreu somente em virtude das perdas por evapotranspiração, medidas pela variação de massa no lisímetro, que somaram 3,6 mm e 2,5 $\mathrm{mm} \mathrm{d}^{-1}$, respectivamente (Figura 4A). As taxas de variação da evapotranspiração, Figura 4B, apresentaram valores mais elevados durante o período entre 12 e 15 h, em decorrência da maior insolação e temperatura neste horário, conforme registros da Estação Meteorológica do IAPAR, localizada ao lado dos lisímetros. No início do terceiro dia procedeu-se à drenagem do lisímetro, que foi indicada, com alta precisão, pelo decréscimo brusco decréscimo de massa de 2,9 mm no período entre 8 e 9 h (Figura 4B); em seguida, o rápido acréscimo de massa foi devido à ocorrência de precipitação de $0,7 \mathrm{~mm}$, verificada logo após a drenagem; nesse dia, a lâmina perdida por evapotranspiração totalizou 4,1 mm. 


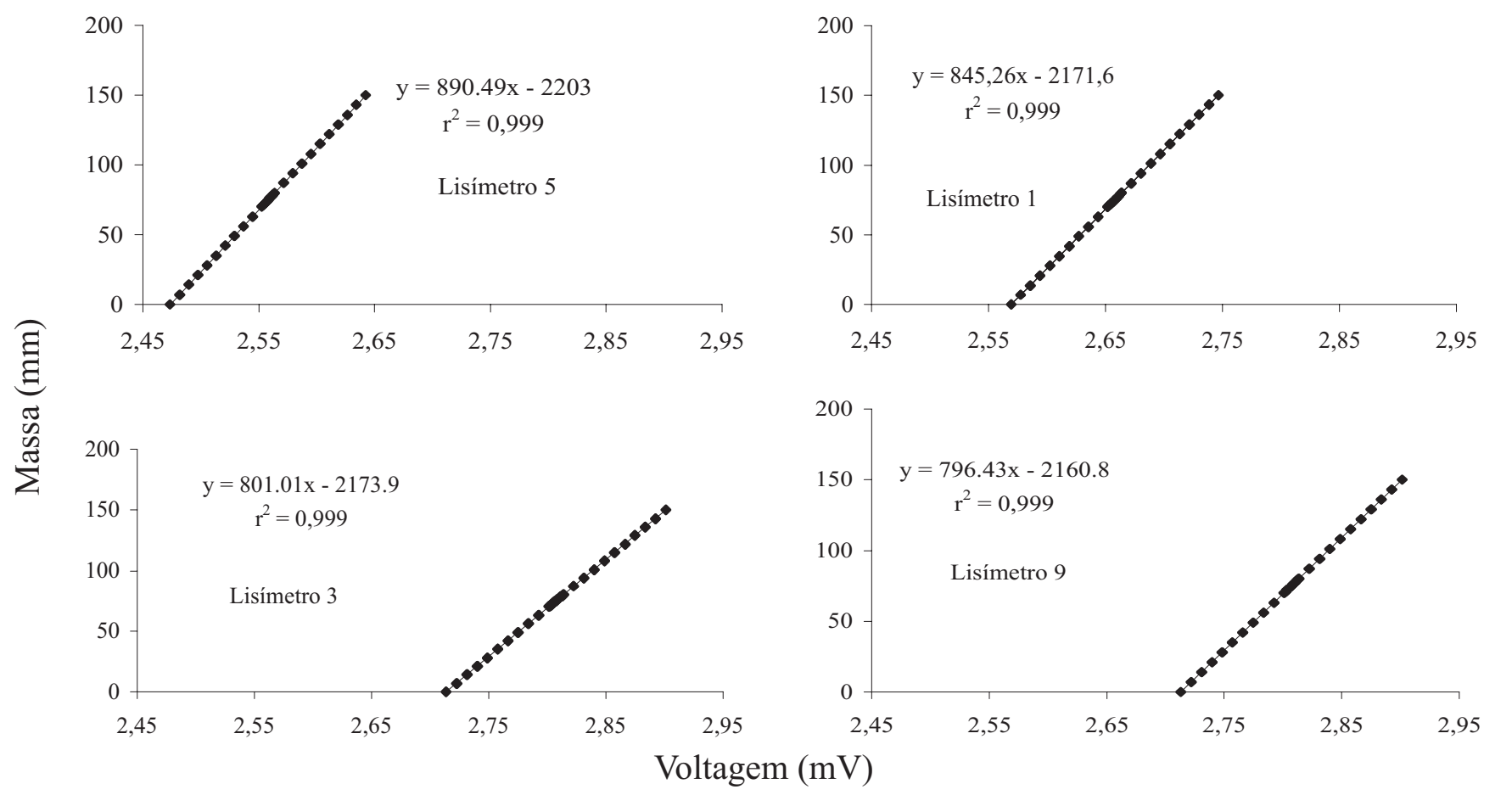

Figura 3. Relação entre variação de massa e voltagem em quatro lisímetros

A.

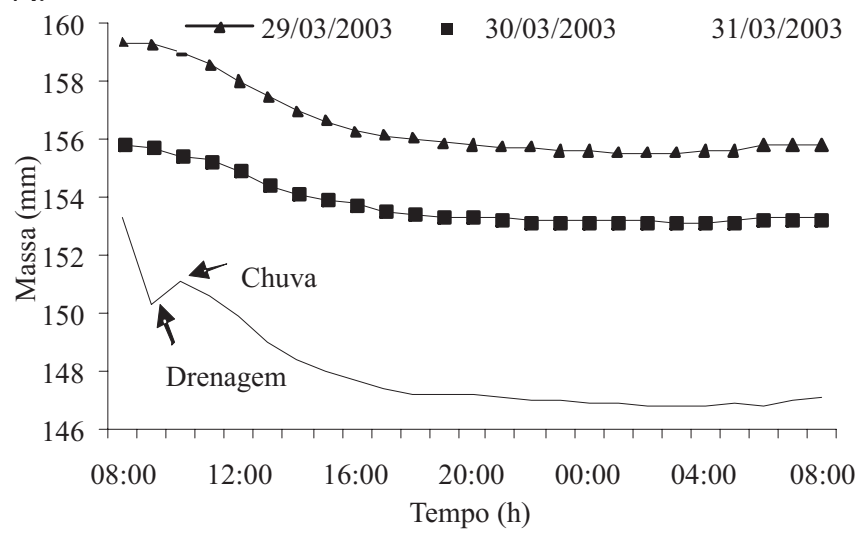

B.

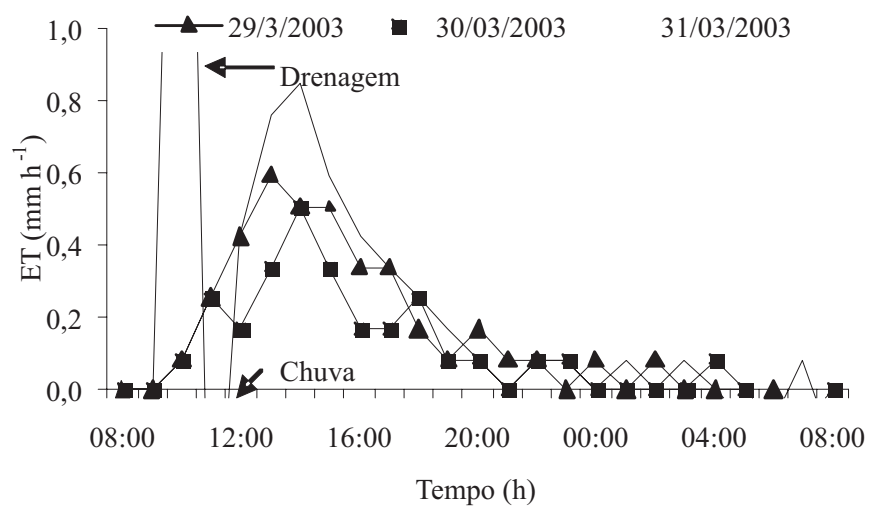

Figura 4. Variação horária de massa equivalente em mm (A) e evapotranspiração (B) de um dos lisímetros instalados durante o período de três dias
Nas medidas de variação de massa apresentadas na Figura 4 e nas determinações realizadas posteriormente durante o período de seis meses, não foram observados acréscimos de massa devidos às mudanças de temperatura da célula de carga, conforme constatado por Silva et al. (1999) e Fietz et al. (2003), em virtude, talvez, do melhor isolamento térmico dos sensores, decorrente da maior profundidade dos lisímetros deste trabalho.

Apesar da alta acurácia da célula de carga e do sistema de aquisição de dados, as medidas tomadas durante vários dias após a construção dos lisímetros indicaram que a chuva reduz a precisão das medidas durante os períodos com precipitação e o vento é o fator mais limitante para obtenção de medidas com alta resolução temporal, de menos de $10 \mathrm{~min}$, conforme também comentado por Howell (1995), Bergamaschi et al. (1997) e Pereira et al. (2002) porém medidas com intervalo de 1 h, como mostradas na Figura 3, apresentam bons resultados em razão da suavização das variações instantâneas das oscilações de massa causadas pelo vento, que é possível registrando-se médias horárias obtidas de 1.200 leituras, tomadas a cada 3 s. Nessas condições, os lisímetros testados apresentam acurácia para detecção de mudanças de massa da ordem de 0,1 mm, o que é adequado para a maioria das aplicações de campo.

\section{CONCLUSÕES}

1. Os lisímetros testados apresentam componentes robustos e duráveis, possuindo um sistema de pesagem de elevada acurácia. 
2. A automação da tomada e armazenamento de leituras facilita a operação contínua do sistema, tornando-os adequados, tanto para medições durante longos períodos como para determinações ao longo do dia.

3. A capacidade de detecção de mudanças de massa da ordem de $0,1 \mathrm{~mm}$, em intervalos de até $1 \mathrm{~h}$, habilita o uso desses lisímetros para a maioria das aplicações de campo.

\section{LITERATURA CITADA}

Allen, R. G.; Fischer, D. K. Direct load cell-based weighing lysimeter system. In: Allen, R. G.; Howell, T. A.; Pruitt, W. O.; Water, I. A.; Jensen, E. (Eds.) Lysimeter for evapotranspiration and environmental measurements. New York: American Society of Civil Engineers, 1991. p.114-124.

Bergamaschi, H.; Santos, M. L. V.; Medeiros, S. L. P.; Cunha, G. R. da. Automação de um lisímetro de pesagem através de estação meteorológica, a campo. In: Congresso Brasileiro de Agrometeorologia, 10, 1997, Piracicaba. Anais... Piracicaba: SBA,1977,p.176-177.
Campeche, L. F. S. M. Construção, calibração e análise de funcionamento de lisímetros de pesagem para determinação da evapotranspiração da cultura da lima ácida "Tahiti” (Citrus latifólia Tan.). Piracicaba: ESALQ/USP, 2002. 67p. Dissertação Mestrado

Fietz, C. R.; Silva, F. C.; Urchei, M. A. Instalação e calibração de lisímetros de pesagem para medida de evapotranspiração de culturas anuais. In: Congresso Brasileiro de Agrometeorologia, 13, 2003, Santa Maria. Anais... Santa Maria: SBA, 2003. p.411-412.

Howell, T. A.; Schineider, A. D.; Dusek, D. A.; Marek, T. H.; Steiner, J. L. Calibration and scale performance of Bushland weighing lysimeters. Transactions of the ASAE, St. Joseph, v.38, n.4, p.1019-1024, 1995.

Meshkat, M.; Warner, R. C.; Walton, L. C. Lysimeter design, construction, and instrumentation for assessing evaporation from a large undisturbed soil monolith. Transactions of the ASAE, St. Joseph, v.15, n.4, p 303-308. 1999.

Pereira, A. R.; Santiago, A. V.; Maggiotto, S. R.; Folegatti, M. V. Problemas operacionais com lisímetros de pesagem durante a estação chuvosa e em dias secos com rajadas de vento. Revista Brasileira de Agrometeorologia, Santa Maria, v.10, n.1, p. 51-56, 2002.

Silva, F. C.; Folegatti, M. V.; Magiotto, S. R. Análise do funcionamento de um lisímetro de pesagem com célula de carga. Revista Brasileira de Agrometeorologia, Santa Maria, v.7, n.1, p.53-58, 1999. 